\title{
FORMAÇÃO DE PROFESSORES DA EDUCAÇÃO PROFISSIONAL NOS PROGRAMAS ESPECIAIS DE FORMAÇÃO PEDAGÓGICA
}

\author{
M. M. M. VIEIRA ${ }^{1 *}$, J. A VIEIRA ${ }^{1}$ e R. PASQUALLI ${ }^{2}$ \\ ${ }^{1}$ Instituto Federal de Educação, Ciência e Tecnologia do Rio Grande do Sul - Campus Sertão \\ ${ }^{2}$ Instituto Federal de Educação, Ciência e Tecnologia de Santa Catarina - Campus Chapecó \\ mariland@unochapeco.edu.br ${ }^{*}$
}

Artigo submetido em outubro/2014 e aceito em dezembro/2014

DOI: $10.15628 /$ rbept.2014.3551

\section{RESUMO}

O trabalho trata da formação de professores por meio do Programa Especial de Formação Pedagógica de Docentes para a Educação Profissional que se diferencia dos tradicionais cursos de formação docente, requerendo reflexão sobre as práticas que estão sendo neles desenvolvidas. Analisa como egressos de um desses Programas de Formação caracterizam seu processo de formação docente, avalia em que medida ele provoca alterações nas concepções dos egressos e identifica desafios que esses se deparam no seu processo de constituição como docente. A abordagem metodológica adotada foi a pesquisa qualitativa com análise de dados empíricos coletados através de entrevista semiestruturada realizada com dezenove egressos do Curso de Formação Pedagógica de Docentes do IFRS Campus Sertão. Os relatos obtidos foram analisados com a interlocução dos estudos de Garcia (1999), Nóvoa (1997), Pimenta (1999), Bolzan; Isaia (2005), dentre outros. Os resultados indicam que os Programas Especiais de Formação Pedagógica de Docentes contribuem significativamente no processo de constituição da professoralidade dos professores da educação profissional, qualificando-os para a docência.

PALAVRAS-CHAVE: Formação de Professores, Educação Profissional, Programa Especial de Formação Pedagógica.

\section{TRAINING OF PROFESSIONAL EDUCATION TEACHERS IN SPECIAL PROGRAMS OF PEDAGOGICAL FORMATION}

\begin{abstract}
The work is about the training of teachers through the Special Program for Teacher's Pedagogical Training for Professional Education, which differs from traditional teacher's training courses, requiring consideration of the practices that being developed in them. Analyzes how the graduates of these Training Programs featuring her teacher training process, assesses the extent to which it causes changes in the conceptions of graduates and identifies challenges that they face in their constitution process as a teacher. The methodological approach adopted was the qualitative research with empirical data
\end{abstract}

analysis collected through semi-structured interviews conducted with nineteen graduates of the Pedagogical Training Course for Teachers of IFRS - Campus Sertão. The obtained reports were analyzed with the dialogue of studies from Garcia (1999), Nóvoa (1997), Pimenta (1999), Bolzan; Isaia (2005), among others. The results indicate that the Special Program for Teacher's Pedagogical Training contribute significantly in teacher profession constitution process of teachers of professional education, qualifying them for teaching.

KEYWORDS: Teacher Training, Professional Education, Special Program of Teacher's Training. 


\section{INTRODUÇÃO}

Os estudos sobre a formação de professores da educação profissional realizados até 2009 tiveram como foco a revisão histórica da constituição da área e legislações a ela pertinentes, tais como os de Paterossi (1994) e de Machado (2008). O trabalho de Oliveira (2010) concluiu que o tema vinha sendo pouco e mal tratado no Brasil porque não era considerado prioritário, mas eventual, sem marcos regulatórios próprios, efetivado através de programas emergenciais, com ausência de políticas públicas de formação.

A partir de 2007 o oferecimento de educação profissional se expandiu e se estruturou no país com a criação do PROEJA, dos Institutos Federais de Educação, Ciência e Tecnologia, PRONATEC, Brasil Profissionalizado, dentre outras iniciativas. A produção acadêmica relativa à educação profissional e à formação dos seus professores também foi ampliada ${ }^{1}$, porém as políticas de formação dos seus professores não tem alcançado o reconhecimento necessário e continuam se caracterizando por dois aspectos: a descontinuidade e não obrigatoriedade. A regulamentação do oferecimento de educação profissional foi feita por meio de decretos - como os de n 2208/97 e no 5154/2004 - que não exigem formação específica para o ingresso na docência, que poderia ser suprida pela experiência profissional na área e, se oferecida em serviço, ocorreria por meio de programas especiais de formação pedagógica.

Embora desde a década de 1990 se defenda a criação de cursos de licenciatura nos diversos ramos da educação profissional, essa medida ainda não foi implementada de forma significativa, embora a legislação que instituiu os Institutos Federais preveja como uma de suas atribuições o oferecimento de cursos de formação de professores. Mesmo a mais recente legislação na área as Diretrizes Curriculares Nacionais para a Educação Profissional Técnica de Nível Médio, aprovada pela Resolução no 06/12, estabelece que essa formação possa ser adquirida por meio de diversas formas, além da licenciatura: programas de formação pedagógica, cursos de especialização, certificação das experiências, segunda graduação ou "outras formas".

As iniciativas no sentido de formar professores para a educação profissional ainda tem sido incipientes e em muitos locais têm sido oferecidas por meio de cursos de formação pedagógica. Um desses cursos é o lócus do presente trabalho, que foi desenvolvido no Instituto Federal de Educação, Ciência e Tecnologia do Rio Grande do Sul (IFRS) - Campus Sertão e teve como propósito investigar as contribuições desse programa de formação de professores oferecido pela instituição.

Assim, na primeira parte encontram-se contextualizados os Programas Especiais de Formação Pedagógica de Docentes segundo a legislação vigente e na instituição pesquisada, incluindo seus aspectos constitutivos. Na segunda parte é apresentada a visão de professores egressos do referido Programa apontando seu perfil, razões de ingresso e contribuições para a formação docente.

\footnotetext{
${ }^{11}$ Levantamento da produção do conhecimento relativo ao período de 2010 a 2014 realizados pelos autores apontou a existência de 20 teses e dissertações no site da CAPES.
} 


\section{PROGRAMA DE FORMAÇÃO PEDAGÓGICA DE DOCENTES PARA A EDUCAÇÃO PROFISSIONAL}

Os Programas Especiais de Formação Pedagógica de Docentes foram instituídos pela Resolução no 2/97, de 26/06/1997 do Conselho Nacional de Educação que dispôs sobre a formação pedagógica de docentes para as disciplinas do currículo do ensino fundamental e médio e da educação profissional em nível médio. Esses programas podem ser ministrados em cursos regulares de licenciatura, em cursos regulares para portadores de diplomas de educação superior ou em programas especiais de formação pedagógica. Não se diferenciam dos previstos nas legislações anteriores, exceto pelo fato de preverem uma organização curricular baseada em núcleos. Sua carga horária foi fixada em no mínimo 540 horas, incluindo a parte teórica e prática com duração mínima de 300 horas, o que faz com que, excetuando-se a parte prática, a formação pedagógica se limite a 240 horas, fornecendo ao seu concluinte o título de licenciado. Essa é uma das principais críticas dos estudiosos da formação de professores para a educação profissional, ou seja, o aligeiramento da formação do professor.

Em 1ㅇ de julho de 2015, por meio da Resolução CNE № 2 que definiu Diretrizes Curriculares Nacionais para a formação inicial em nível superior e para a formação continuada, os cursos de formação pedagógica continuam a existir com as mesmas características, ou seja, emergencial e provisório, conforme expresso em seu art. 14.

Art. 14. Os cursos de formação pedagógica para graduados não licenciados, de caráter emergencial e provisório, ofertados a portadores de diplomas de curso superior formados em cursos relacionados à habilitação pretendida com sólida base de conhecimentos na área estudada, devem ter carga horária mínima variável de 1.000 (mil) a 1.400 (mil e quatrocentas) horas de efetivo trabalho acadêmico, dependendo da equivalência entre o curso de origem e a formação pedagógica pretendida.

Referida legislação ampliou a carga horária total do curso, organizando sua estrutura em três núcleos, além do estágio supervisionado, que continua fixado em 300 horas. 0 prazo para revisão dos cursos e programas em funcionamento foi fixado em dois anos, ou seja, os projetos de curso em andamento devem ser revistos até julho de 2017.

A provisoriedade e a emergencialidade do programa também esta expressa no $\S 70$ do artigo 14 previu a avaliação do desenvolvimento desses cursos no prazo máximo de 5 (cinco) anos, a ser efetivada pelo Ministério da Educação, em articulação com os sistemas de ensino e com os fóruns estaduais permanentes de apoio à formação docente e cabe a esses órgãos definir prazo para sua extinção em cada estado da federação.

$\mathrm{Na}$ instituição envolvida neste trabalho, o Programa foi criado em 2010 e conta com ingresso de sete turmas, sendo que cinco já o concluíram. Em 2010 foram oferecidas 70 vagas e após esse ano, são ofertadas 40 vagas anuais. Atualmente frequentam duas turmas que totalizam 65 alunos oriundos de cidades do Estado do Rio Grande do Sul e Santa Catarina.

Inicialmente a preocupação do Programa era qualificar professores que atuam na instituição ofertante. Porém, passou a atender profissionais ligados a outras instituições de educação profissional da sua área de abrangência, cumprindo o que estabelece a Resolução CNE 
$\mathrm{n}$ 2, de 26 de junho de 1997. No parágrafo único do art. 1 을 consta que referidos programas foram criados para "[...] suprir a falta nas escolas de professores habilitados, em determinadas disciplinas e localidades, em caráter especial". Assim, o Programa atende portadores de diploma de curso superior, sendo que a instituição confere a compatibilidade entre a formação do candidato e a área para a qual pretende habilitar-se.

O curso ocorre em regime especial, com aulas nos fins de semana e sua estrutura curricular totaliza 956 horas, organizadas nos núcleos definidos pela Resolução CNE no 2, de 26 de junho de 1997. A parte prática ocorre através de estágio supervisionado que totaliza $400 \mathrm{~h}$ e é realizada em instituições de ensino que oferecem cursos de educação profissional, incluindo a própria instituição, que mantém cursos de ensino médio integrado, concomitância externa e subsequente em três áreas: agropecuária, informática e comércio.

\section{CONTRIBUIÇÕES DO PROGRAMA DE FORMAÇÃO PEDAGÓGICA NA PERSPECTIVA DOS EGRESSOS}

Os sujeitos envolvidos nesta pesquisa foram dezenove egressos de seis turmas do Programa de Formação Pedagógica de Docentes para a Educação Básica e Profissional do IFRS - Campus Sertão, concluintes entre os anos de 2010 e 2014 e que exercem a docência na área da educação profissional. A pesquisa foi realizada após aprovação do Comitê de Ética em Pesquisa e os egressos foram contatados por e-mail e foram agendadas e realizadas entrevistas e assinados os termos de consentimento livre e esclarecido. A identidade dos entrevistados foi mantida em sigilo e, para tanto, atribuiu-se um código para cada participante (número de ordem da entrevista e turma frequentada -1 a 6$)$.

A entrevista foi composta por doze questões ${ }^{2}$, cuja duração foi em média 45 minutos. Foram gravadas, transcritas e analisadas com base na análise de conteúdo proposta por Bardin (2002) e os dados organizados em categorias que compuseram o estudo. A análise foi realizada com a interlocução dos estudos de Garcia (1999), Nóvoa (1997), Pimenta (1999), Bolzan; Isaia (2005), dentre outros dentre outros. A seguir é apresentada a análise dos dados coletados organizados em categorias que emergiram do estudo.

\subsection{Caracterização do processo de formação dos docentes egressos}

Um dos objetivos da pesquisa foi analisar como os professores da educação profissional caracterizam seu processo de formação docente e para tanto foram investigadas as suas trajetórias de formação profissional. Os dados coletados indicam que quinze egressos são bacharéis em áreas como Agronomia, Administração, Direito, Engenharia de Alimentos, Economia, Engenharia Mecânica, Nutrição; dois entrevistados têm formação em curso de Tecnologia em Gestão da Produção Industrial e Desenvolvimento Rural Sustentável e Agroecologia; dois participantes frequentaram cursos de bacharelado em Ciências Biológicas e Geografia.

Esses resultados confirmam dados de outros estudos que traçaram um perfil dos professores que atuam na educação profissional, já que nos cursos de nível técnico há uma grande

\footnotetext{
${ }^{2}$ Para esse trabalho foram analisadas apenas quatro questões.
} 
variedade de áreas e os profissionais que atuam nas disciplinas técnicas tem formação na área específica em que lecionam, como afirma Soares (2008, p. 9):

São trabalhadores os educadores que trabalham com o ensino técnicoprofissionalizante. Suas histórias de vida foram construídas no mundo do trabalho e na formação técnica. As experiências acumuladas enriquecem seus conhecimentos e os aproximam sobremaneira dos jovens que acorrem para a educação profissional.

Tendo em vista esse perfil, os egressos foram questionados sobre as razões para o ingresso na atividade docente, sendo que as respostas obtidas são: quinze entrevistados (E2T3; E3T2; E4T4; E5T4; E6T1; E7T2; E8T5; E9T2; E10T5; E12T2; E13T1; E14T4; E15T4; E17T4; E18T6) já atuavam na sua área de formação em empresas durante o período diurno e buscaram o magistério como oportunidade para melhorar a renda familiar. Quatro deles (E2T3; E5T4; E9T2; E14T4) relataram que já trabalhavam com formação profissional em empresas e por isso o exercício da docência foi uma transição natural e muitos se identificavam com a profissão docente e foram deixando o emprego anterior e dedicando-se somente à docência. Um entrevistado (E1T5) ingressou no magistério por influência de seus professores do mestrado, que o incentivou a assumir aulas e atividades de monitoria durante o curso; três entrevistados (E11T2; E16T3; E19T5) atuavam na docência da educação profissional - ensino médio ou superior - antes do ingresso no Programa.

Esse ingresso na docência tanto representou um abandono do trabalho como técnico quanto pode ser com ele compartilhado. De modo geral, a opção inicial pelo ingresso deve-se à necessidade de melhorar ou complementar os rendimentos financeiros ou como opção de trabalho em horário diferenciado do que já atuavam na empresa, especialmente em cursos noturnos.

Um dos aspectos mais significativos relatados é que muitos egressos não haviam cogitado a possibilidade de ser professor durante a escolha do curso de graduação porque se sentiam desmotivados pela representação social da atividade docente, ou seja, tinham preconceito em relação à profissão devido aos baixos salários percebidos pela categoria profissional. Esse fato nos leva a refletir sobre como esse aspecto interfere na construção da subjetividade docente que, segundo Burnier et al (2007) está marcada "pelas experiências vividas pelos indivíduos ao longo de suas vidas, pelos discursos, pelas instituições e grupos aos quais tiveram acesso, participantes também da construção dos significados que esses docentes irão conferir às suas experiências em geral e à docência em particular.

Outro aspecto a ressaltar é que, embora não tenha sido a causa predominante da escolha da profissão docente, vários entrevistados mencionaram a influência dos ex-professores do curso de graduação ou de mestrado que foram incentivadores dessa escolha. Esse incentivo veio de forma direta, por meio de conselhos e orientações, ou indireta, ao proporcionar vivências de experiências docentes em estágios e monitorias. Outros entrevistados também mencionaram que a empatia pelo professor os fez gostar da profissão e esses tornara-se referência para seguirem a carreira pela forma como trabalhavam, sendo considerados de bons profissionais/cidadãos na sociedade. Assim, concorda-se com Isaia e Bolzan $(2009$, p.12) para quem "o processo reflexivo e as relações interpessoais constituem o componente intrínseco ao processo de ensinar, de 
aprender, de formar-se e, consequentemente, desenvolver-se profissionalmente em direção à autonomia docente".

Foram investigadas também as razões para ingresso no curso de formação pedagógica, tendo sido apontadas pelos entrevistados as seguintes: seis já trabalhavam como docentes e ingressaram com o intuito de melhorar suas práticas de ensino (E1T5; E2T3; E9T06; (E12T2, E13T1; E15T4; E19T5); oito buscaram formação para ingressar na profissão docente para ampliar as possibilidades de campo de trabalho ou complementação da renda (E4T4; E5T4; E6T1; E7T3; E8T5; E11T2; E16T3; E18T6); três cursaram o Programa para cumprir a exigência legal da instituição onde trabalham, pois o edital do concurso público no qual foram aprovados exigia essa habilitação (E3T2; E14T4; E6T1); um egresso buscou o Programa para realização profissional (E17T4).

Nesta dimensão encontram-se razões de ordem prática (ampliação de oportunidades, melhoria da renda familiar, exigência legal) e pedagógicas para o ingresso no Programa. Os entrevistados relataram a necessidade de melhorar sua prática docente adquirindo habilidades e saberes próprios dessa profissão, corroborando com o que afirmam Isaia e Bolzan $(2010$, p. 8) que destacam que a aprendizagem da docência:

[...] caracteriza-se pelo processo de profissionalização docente, a partir da compreensão de seu inacabamento, da tomada de consciência de que nesse processo são ensinantes e aprendentes simultaneamente e da ênfase na prática docente assentada nas reflexões e nas interações da/na aula universitária.

3.2 Diferenças entre cursos de formação da área específica e a formação de professores.

A pesquisa também pretendeu investigar as diferenciações que se colocam entre a formação na área específica dos professores da educação profissional e a sua formação docente. Assim, para três entrevistados o principal conflito apontado foi a diferença de conteúdo entre as áreas, como revela a fala de dois entrevistados:

$\mathrm{Na}$ Biologia a gente trabalha com o funcionamento do corpo, dos organismos e na licenciatura você está trabalhando com a consciência da pessoa, como ela vai ler e interpretar isso. O desafio na licenciatura é muito maior que o bacharelado. (E15T4).

No bacharel em Artes o curso te prepara para ser artista, para desenvolver uma poética e uma arte, que você se descubra. Já na licenciatura, você tem que descobrir a poesia do outro, a linguagem do outro. (E7T1)

Outro aspecto ressaltado pelos entrevistados foi a pouca preocupação com a prática, por parte das ciências humanas e dos cursos de formação pedagógica, como afirmam os seguintes entrevistados:

Mas na educação profissional a gente tem que focar, o professor tem que focar naquilo que vai ser útil para o aluno, no seu dia a dia. (E5T4)

Nós enquanto técnicos que a gente se forma, nós somos muito objetivos e práticos. Ai quando entra no curso de formação tem muita teoria e tu tem que estudar as teorias e tem que debater (E13T1). 
O curso de formação tem a parte teórica, mas a gente procura trazer para o contexto atual e aquela discussão que está em voga (E16T3).

Embora os processos práticos sejam importantes na educação profissional, eles requerem do professor habilidades didático-pedagógicas para estabelecer a relação com a teoria, pois processos e técnicas demandam modos específicos de aprendizagem e a tendência de priorizar o polo prático do ensino faz com que, muitas vezes, o professor descuide-se das necessárias reflexões intelectuais acerca dos conteúdos dessa ação, o que se constitui no grande dilema da educação profissional. Kuenzer (2002, p. 10) ressalta a importância da ação mediadora do professor para estabelecer a necessária articulação entre teoria e prática, pois,

[...] é preciso considerar que a prática não fala por si mesma; os fatos práticos, ou fenômenos, têm que ser identificados, contados, analisados, interpretados, já que a realidade não se deixa revelar através da observação imediata; é preciso ver além da imediaticidade para compreender as relações, as conexões, as estruturas internas, as formas de organização, as relações entre parte e totalidade, as finalidades, que não se deixam conhecer no primeiro momento, quando se percebem apenas os fatos superficiais, aparentes, que ainda não se constituem em conhecimento.

A dificuldade de identificar a aplicabilidade de alguns conteúdos estudados no curso foi outro motivo de tensões, que foi apontado por três entrevistados (E11T2; E13T1; E18T6). Exemplificamos com a epígrafe a seguir:

No início eu pensava: porque eu preciso estudar isso se a minha área não tem nada a ver? Mas depois com as leituras e as aulas a gente consegue fazer um link, compreende que você precisa saber o que passou a sociedade, que isso está inserido na tua disciplina para que você possa melhorar as aulas, sim (E18T6).

Essas falas revelam o modelo da racionalidade técnica que compreende a educação como uma ciência aplicada, restringe a atuação do professor a um técnico que, com base num conjunto de prescrições recebidas em seu curso de formação, desenvolve sua atividade profissional com a aplicação de teorias e técnicas. Para Gomes (1992, p. 26) “[...] Segundo o modelo da racionalidade técnica, a atividade do profissional é, sobretudo, instrumental, dirigida para a solução de problemas mediante a aplicação rigorosa de teorias e técnicas científicas". Trata assim da epistemologia da prática que foi herança do positivismo e que serviu de referência para a educação e socialização dos profissionais em geral e dos docentes em particular durante todo o século XX).

As características distintivas próprias de cada profissão também foram lembradas:

Eu acho que na organização, na preparação que tem que se ter. Agora eu estou terminando o curso de Formação e o nível que tem que se ter, o modo de dar aula pro ensino técnico ou pra uma pós-graduação, são aulas que você tem que dar diferente. Com a formação toda tu percebe o que tem que dar de aula pra cada aluno. Eu vi bastante diferença (E8T5).

Como o curso é interdisciplinar a visão é muito diferente. Nós temos ali que fecham grupos com as ideias, mas eles são constituídos pelas ideias, se tu entrevistares um grupo ele vai ter a mesma visão, às vezes sai um pouco diferente. 
Mas nesse sentido foi tranquilo porque tem que existir diálogo, diálogo é importante (E10T5).

Eu acredito que na parte prática, por exemplo: eu jamais pensei fazer um TCC na licenciatura. Eu acho que isso foi um processo que apavorou todo mundo, então como sugestão de melhoria do curso eu acho que trabalhar a mentalidade do povo que vem de outras áreas um pouco antes pra poder desempenhar melhor 0 papel (E2T3).

Entretanto houve seis entrevistados (E3T2; E6T1; E9T3; E19T5; E1T5; E4T4) que não percebem conflitos ou tensões entre as duas áreas de formação. O Programa Especial de Formação Pedagógica de Docentes investigado, conforme enunciado no perfil é frequentado por professores graduados em várias áreas distintas. Este contexto proporciona diversidade de subjetividades construídas ao longo do processo de formação e que influenciam nas relações que se estabelecem entre eles na sala de aula e em relação ao currículo do curso. Os dados parecem sugerir que quando a formação inicial ocorreu em cursos da área das ciências humanas há maior semelhança de pensamento e menores tensionamentos, enquanto que os graduados em áreas distintas parecem ter maiores dificuldades em compreender as especificidades dos cursos de formação de professores.

\subsection{Contribuições do Curso de Formação Pedagógica para a Docência}

Outro objetivo da pesquisa foi avaliar em que medida o processo de formação para a docência provoca alterações nas concepções dos entrevistados e contribui para a formação como pessoa e docente. Nesta direção, pode-se afirmar que os entrevistados demonstraram satisfação com o curso realizado e destacam as principais contribuições.

Segundo sete egressos (E2T3, E3T2, E4T4, E5T4, E8T5, E13T1, E17T4), o curso de formação pedagógica contribuiu para torná-los mais sensíveis às diferenças existentes entre as pessoas, tornando-os mais humanos e compreensivos com a situação de cada aluno, abrindo novos horizontes para o exercício da docência frente aos desafios de inclusão social. Essas manifestações podem ser percebidas nos trechos a seguir:

A formação pedagógica te abre novos horizontes porque se não tem essa formação tu ficas meio que restrito, tu só visualiza como professor, tu sabe como que tu deve ser e como deve ser esse professor ou não, mesmo sendo aluno. E a formação te abre horizontes teóricos e você começa a entender o porquê de certas visões, porque acontece isso, porque devo fazer dessa forma e assim por diante (E4T4).

Eu aprendi, por exemplo, a lidar com a presença dos índios do Campus. Primeira coisa que preciso fazer é ouvir os alunos, tentar puxar para a discussão, ouvir a realidade deles, não adianta aplicar um exercício para alunos que não sabem escrever bem. No primeiro ano tive um "pé atrás" com os alunos índios, cansei de explicar para eles em grupos separados, porque não te entendem por questão de idioma. Se você reparar eles estão sempre perto de alguém diferente porque precisam de um tradutor e se você reparar eles estão sempre com sede de conhecimento, querem aprender e o esforço deles é fantástico, só que precisam 
de atendimento especial. Isso aí não é passar eles em vão, mas ter uma compreensão melhor, é você abordar de outra forma (E8T5).

Esse ano eu tive de enfrentar certo conflito, pois bem no dia da minha aula foram mortos dois agricultores por indígenas. Na minha turma tinha alunos indígenas e um menino filho de agricultor lá da região. Como é que tu faz? 0 técnico não sabe mediar isso, então a licenciatura te ajuda a mediar isso porque te dá certo equilíbrio, te ensina a ouvir os dois lados e ponderar, não dizer quem tem razão, mas achar um meio termo. A licenciatura te diz que não existe uma linha, mas sim que existem vários trajetos para seguir o mesmo caminho (E13T1).

A mudança de postura e de visão também ocorreu em relação à atividade docente que foi mencionada por outros quatro colaboradores desta pesquisa (E1T5; E12T2; E13T1; E16T3) onde informaram ter alterado sua visão sobre como organizar o trabalho em sala de aula e passaram a compreender melhor o papel do professor na educação profissional. Essas constatações podem ser vistas nas falas que seguem:

Eu imaginava que o professor antes era só aquele que transmitia o conhecimento, hoje em dia eu vejo que ele tem uma função muito além desta de transmitir o conhecimento, mas de como utilizar técnicas (E12T2).

A formação me ajuda a pensar diferente, até porque a minha formação não sei se continua sendo, nós tivemos muito a nível de ensino básico e técnico e você tem que ter outra visão. Tu não vai ter uma visão do aluno trabalhar sozinho (E13T1).

Nesta direção, Nóvoa (2003) enfatiza que a construção do conhecimento profissional docente implica dimensões da experiência, da reflexão e da formulação. Para ele, dificilmente será construída uma docência se os professores não forem capazes de valorizar suas experiências formação experiencial. A experiência não é formadora por si só, sendo necessária a reflexão sobre a experiência e, portanto, de uma formação reflexiva.

Um dos principais objetivos dos ingressantes no curso era "aprender a dar aulas", ou seja, buscavam aprender técnicas de ensino mais adequadas das que faziam uso em sala de aula, o que reforça o modelo da racionalidade técnica. Assim, em várias entrevistas há fragmentos indicativos que o curso auxiliou nesse sentido, embora muitos deles deixem evidente outras expectativas que o curso não contemplou, conforme podem ser vistos nos depoimentos que seguem:

Alguns exemplos bastante positivos de se trabalhar em sala de aula, alguns textos, algumas coisas mesmo. Não vou negar que algumas disciplinas deixaram a desejar, por uma questão de irem bastante para o tradicional, talvez isso deva ser trabalhado melhor dentro do curso de Formação Pedagógica, pois havia professor que pregava uma visão não tradicional, mas nas suas próprias ações me direcionam pra visões tradicionais (E10T5).

O que eu acho que falta? Direcionar para o técnico mesmo, porque é uma formação para o nível básico profissional. Colocar, por exemplo, que eu vou dar uma aula para o técnico em alimentos, ai tem que dizer aonde que eu tenho que criar a minha aula, porque o curso foi muito básico, como se fosse uma pedagogia. E muitas discussões elas passavam pela parte técnica, mas elas não aprofundavam a parte técnica (E15T4). 
Já os egressos E2T3; E6T1; E7T3; E11T2; E15T4; E18T6 apontaram que o curso auxiliou na prática de ensino, contribuindo para melhorar as atividades docentes e proporcionou reflexão sobre novas formas de ensinar. Esses posicionamentos positivos em relação ao curso são explicitados abaixo:

Ele mudou, porque me deixou mais interativo, ensinou algumas metodologias que se precisa aplicar em sala de aula, então tu tem que repensar porque a tua aula hoje é de um jeito, mas amanha tu não pode fazer absolutamente igual porque não vai funcionar. E o que se faz então? Aqui no instituto mesmo a gente utiliza muito o datashow e se faltou luz o técnico vai parar a aula e ir embora. Quem estudou a pedagogia vai ter um plano porque o técnico não tem plano $B$, ele pode ter o plano para uma área específica, mas não para a sala de aula. (E6T1)

[...] com as disciplinas de didática e psicologia eu vejo que a forma de avaliação, a forma de dar aula, eu já estou conseguindo colocar em prática, tá me ajudando muito. (E18T6)

O curso me permitiu fazer um planejamento melhor da aula, fazer a introdução, o desenvolvimento e a conclusão com análise crítica no final de aula, expor aos alunos e pedir um feedback no final pra ver se os objetivos propostos foram alcançados e com isso fazer uma aula de análise constante daquilo que foi proposto em sala de aula. A gente pode com isso fazer uma aula bacana e ver se atingiu o aluno, porque sem ele a gente está fora. (E2T3).

Para Pimenta (1999), esses aspectos positivos do curso apontados pelos egressos podem ser considerados saberes pedagógicos que são identificados como "ter didática", isto é, saber ensinar, o que supera o domínio de estratégias de ensino e de avaliação. Para ela "[...] os saberes sobre a educação e sobre a pedagogia não geram os saberes pedagógicos. Estes só se constituem a partir da prática, que os confronta e os reelabora. Mas os práticos não o geram só com o saber da prática" (p. 26).

\subsection{Desafios enfrentados pelos professores da educação profissional na docência}

Por fim pretendeu-se identificar os desafios que os professores da educação profissional se deparam durante seu processo de constituição como docente e de que forma constroem estratégias de superação.

Para cinco entrevistados (E2T3; E3T2; E9T3; E11T2; E17T4) o maior desafio é manter-se na docência quando recebem oferta de emprego que tem melhor remuneração. Há um conflito permanente entre fazer o que gostam e ter oportunidades de melhorar o acesso aos bens materiais.

Para sete egressos (E1T5; E4T4; E5T4; E13T1; E14T4; E16T3; E18T6), os maiores desafios da docência referem-se aos estudantes, pois fatores como diferenças de idade entre eles, domínio de conhecimentos prévios insuficientes, falta de preparo para a convivência em grupo e a dificuldade de captar e manter a atenção de todos em aula interferem no exercício da docência. Já para os egressos E8T5 e E10T5 o mais difícil é competir com a tecnologia, como computador e redes sociais, pois o professor é constantemente desafiado a encontrar formas de despertar e manter a 
motivação do aluno pelas aulas, desenvolvendo interesse pelo aprendizado. Representativo desse pensamento é o depoimento que segue:

O tipo de alunos que se tem hoje em dia. Eles não respeitam o professor como antes. Eu acho que não tem como fugir da tecnologia, muitas vezes eu deixo utilizar celular e computador, só proíbo se acaso isso tirar a atenção do aluno e às vezes eles pesquisam na internet e te confrontam. (E8T5).

A forma de avaliar e atribuir nota aos alunos também foi apontado como um desafio para dois docentes (E6T1, E7T3). Segue fala do primeiro:

Meu maior desafio é a avaliação, em como você avalia um aluno, com nota, prova, trabalho, como tu mede isso? O maior conflito é isso em não ser injusto com ninguém.

Por fim, E17T4 apontou como desafiador manter o domínio sobre a turma e para E15T4 é como conciliar prática e teoria nas atividades de sala de aula.

Kuenzer (2002, p. 10) ressalta a importância da ação mediadora do professor para estabelecer a necessária articulação entre teoria e prática, pois, segundo a autora:

[...] é preciso considerar que a prática não fala por si mesma; os fatos práticos, ou fenômenos, têm que ser identificados, contados, analisados, interpretados, já que a realidade não se deixa revelar através da observação imediata; é preciso ver além da imediaticidade para compreender as relações, as conexões, as estruturas internas, as formas de organização, as relações entre parte e totalidade, as finalidades, que não se deixam conhecer no primeiro momento, quando se percebem apenas os fatos superficiais, aparentes, que ainda não se constituem em conhecimento.

Fica evidenciado, portanto, que embora os processos práticos sejam importantes na educação profissional, requerem habilidades didático-pedagógicas para estabelecer a relação com a teoria, pois processos e técnicas demandam modos específicos de aprendizagem.

\section{CONSIDERAÇÕES FINAIS}

Analisando a formação pedagógica de professores da educação profissional, chega-se ao final desta reflexão consciente de que este processo pode se iniciar ainda na formação inicial (graduação) quando os professores motivam seus acadêmicos para a busca da formação pedagógica. Além disso, outros professores optam para a docência a partir de vivências cotidianas e por questões financeiras, o que não deixa de ser um fator de grande influência na atualidade.

Seja por influência ou por necessidade, os sujeitos envolvidos neste trabalho acabaram se apaixonando pela profissão docente e procuram superar os desafios que esta profissão exige, enfrentando obstáculos e tornando-se profissionais/docentes qualificados para a docência e para isso buscam qualificação em Programas Especiais de Formação Pedagógica. 
O conteúdo expresso nas falas dos egressos permite compreender o seu processo de construção da professoralidade e as contribuições do Programa de Formação Pedagógica de Docentes neste processo. Como afirmam Bolzan; Powaczuk (2009, p. 93):

[...] é possível pensar a aprendizagem da docência como um movimento que se realiza a partir das possibilidades internas e das necessidades externas. Estabelecendo-se um processo entre as potencialidades do sujeito e as exigências da profissão, no qual as interações com colegas e alunos assumem uma importância fundamental, na medida em que se constituem como elementos fomentadores da aprendizagem docente.

Chegando-se a uma tentativa de finalização, é importante ressaltar que este trabalho de pesquisa produziu reflexões críticas e/ou confirmou conhecimentos para o desenvolvimento do processo de formação pedagógica de docentes da educação profissional. Esses conhecimentos poderão ser utilizados na construção de alguns conceitos relacionados, colaborando com melhorias dos Programas Especiais de Formação Pedagógica de Docentes.

Essas considerações são inacabadas e requerem ser aprofundadas e melhor validadas em outros trabalhos. Trata-se de tema fecundo para novas investigações, não só para recriar a educação profissional como para possibilitar a formação de profissionais mais autônomos, participativos e críticos, capacitados a refletir e produzir uma educação com qualidade.

\section{REFERÊNCIAS}

1. BARDIN, L. Análise de conteúdo. Lisboa: Edições 70, 2002.

2. BRASIL. CNE/CEB. Resolução no 02/97. Dispõe sobre os programas especiais de formação pedagógica de docentes para as disciplinas do currículo do ensino fundamental, do ensino médio e da educação profissional em nível médio. Disponível em http://portal.mec.gov.br/setec/arquivos/pdf/RCNE_CEB02_97.pdf Acesso em: 25. jul. 2014.

3.

CNE/CEB. Resolução no 6, de 20 de setembro de 2012. Define Diretrizes Curriculares Nacionais para a Educação Profissional Técnica de Nível Médio. Disponível em: $<$ http://portal.mec.gov.br/index.php?option=com content\&view=article\&id=17417\&ltemid= 866> Acesso em: 20.jul. 2014.

4.

Resolução CNE/CP no 2, de 10 de julho de 2015. Define as Diretrizes Curriculares Nacionais para a formação inicial em nível superior (cursos de licenciatura, cursos de formação pedagógica para graduados e cursos de segunda licenciatura) e para a formação continuada. Disponível em: http://portal.mec.gov.br/conselho-nacional-de-educacao/atos-normativos-sumulas-pareceres-e-resolucoes?id=21028. Acesso em: 20.ago. 2015.

5. BOLZAN, D.P.V.; ISAIA, S. Aprendizagem Docente no Ensino Superior: construções a partir de uma rede de interações e mediações. In: UNIrevista. Vol.1, n.1. IV Congresso Internacional de Educação. UNISINOS. São Leopoldo. 2005.

6. BOLZAN, D.P.V.; POWACZUK, A.C.H. Docência Universitária: a construção da professoralidade. In: Revista Brasileira de Formação de Professores. Vol. 1, n. 3, p.90-104, Dez.2009.

7. BURNIER, S.; CRUZ, R.M.R.; DURÃES, M.N.; PAZ, M.L.; SILVA, A.N.; SILVA, I.M.M. Histórias de vida de professores: o caso da educação profissional. In: Rev. Bras. Educ. Rio de Janeiro, 
vol.12 n.35, p. 343-358, maio/ago.2007.

8. GARCIA, C.M. A identidade docente: constantes e desafios. In: Formação Docente. Belo Horizonte, v. 01, n. 01, p. 109-131, ago./dez. 2009. Disponível em: http://formacaodocente.autenticaeditora.com.br/artigo/exibir/1/3/1. Acesso em: 12. dez. 2014.

9. GÓMEZ, A.P. O pensamento prático do professor - a formação do professor como profissional reflexivo. In: NÓVOA. A. (Coord.). Os professores e a sua formação. Lisboa: Dom Quixote, 1992.

10. ISAIA, S.M.A. BOLZAN, D.P.V. Processos Formativos e Docência: Tecendo Redes de Formação na Educação Superior. Belo Horizonte, 2010.

11. KUENZER, A.Z. Conhecimento e competências no trabalho e na escola. Boletim Técnico do SENAC. Rio de Janeiro, v. 28, n. 2, p. 45-68, maio/ago. 2002.

12. MACHADO, L.R. S. Diferenciais inovadores na formação de professores para a educação profissional. In: Revista Brasileira da Educação Profissional e Tecnológica, Ministério da Educação, Secretaria de Educação Profissional e Tecnológica, v. 1, n. 1, jun. 2008. Brasília: MEC/SETEC, 2008.

13. NÓVOA, A. Vidas de professores. Porto: Porto Editora, 1997.

14. OLIVEIRA, M.R.N.S. de. A formação de professores para a educação profissional. In: DALBEN, A.L.; DINIZ, J.; LEAL, L.; SANTOS, L. (Org.). Coleção Didática e Prática de Ensino. Belo Horizonte, Autêntica, 2010, p. 455 - 478. Disponível em: http://www.academia.edu/4894113/Colecao_didatica_e_pratica_de_ensino_-_Livro_3_PDF. Acesso em 10. jun.2014.

15. PETEROSSI, H.G. Formação de professores para o ensino técnico. São Paulo: Loyola, 1994.

16. PIMENTA, S.G. Professor: formação, identidade e trabalho docente. In: (org). Saberes pedagógicos e atividade docente. São Paulo: Cortez, 1999, p. $15-34$.

17. SOARES, A.S. A educação profissional e o professor: fazeres e saberes necessários. In: I Seminário Nacional de Educação Profissional e Tecnológica, 2008, Belo Horizonte. Anais do I SENEPT. Belo Horizonte: CEFET-MG, 2008. 